\title{
Video Article \\ A Gusseted Thermogradient Table to Control Soil Temperatures for Evaluating Plant Growth and Monitoring Soil Processes
}

\author{
Gregory E. Welbaum ${ }^{1}$, Osamah S. Khan ${ }^{1}$, Nezar H. Samarah ${ }^{1,2}$ \\ ${ }^{1}$ Department of Horticulture, Virginia Polytechnic Institute and State University \\ ${ }^{2}$ Department of Plant Production, Faculty of Agriculture, Jordan University of Science and Technology
}

Correspondence to: Gregory E. Welbaum at welbaum@vt.edu

URL: https://www.jove.com/video/54647

DOI: doi:10.3791/54647

Keywords: Environmental Sciences, Issue 116, Thermogradient table, controlled environment, soil temperature modification, LED grow lights, seed germination, soil ecology

Date Published: 10/22/2016

Citation: Welbaum, G.E., Khan, O.S., Samarah, N.H. A Gusseted Thermogradient Table to Control Soil Temperatures for Evaluating Plant Growth and Monitoring Soil Processes. J. Vis. Exp. (116), e54647, doi:10.3791/54647 (2016).

\section{Abstract}

Thermogradient tables were first developed in the 1950s primarily to test seed germination over a range of temperatures simultaneously without using a series of incubators. A temperature gradient is passively established across the surface of the table between the heated and cooled ends and is lost quickly at distances above the surface. Since temperature is only controlled on the table surface, experiments are restricted to shallow containers, such as Petri dishes, placed on the table. Welding continuous aluminum vertical strips or gussets perpendicular to the surface of a table enables temperature control in depth via convective heat flow. Soil in the channels between gussets was maintained across a gradient of temperatures allowing a greater diversity of experimentation. The gusseted design was evaluated by germinating oat, lettuce, tomato, and melon seeds. Soil temperatures were monitored using individual, battery-powered dataloggers positioned across the table. LED lights installed in the lids or along the sides of the gradient table create a controlled temperature chamber where seedlings can be grown over a range of temperatures. The gusseted design enabled accurate determination of optimum temperatures for fastest germination rate and the highest percentage germination for each species. Germination information from gradient table experiments can help predict seed germination and seedling growth under the adverse soil conditions often encountered during field crop production. Temperature effects on seed germination, seedling growth, and soil ecology can be tested under controlled conditions in a laboratory using a gusseted thermogradient table.

\section{Video Link}

The video component of this article can be found at https://www.jove.com/video/54647/

\section{Introduction}

Thermogradient tables are not new and their use has been reported in the literature over several decades ${ }^{1-6}$. Early tables were developed ostensibly for laboratory seed germination testing often on paper substrate over a broad range of temperatures in a single experiment (Figure 1). There are different designs of thermogradient tables but one of the most common consists of a relatively thick rectangular sheet of metal, often aluminum for its corrosion resistance, with a loop of square pipe welded to the bottom at opposite ends. Plastic tubes connect the table inand outlet pipes to temperature controlled, circulating baths that pump the cooled and heated fluid through the pipes on opposite ends beneath the table. The pipe conducts fluid, usually a water-antifreeze (ethylene glycol) mixture, to prevent freezing if the system is to be operated near or below freezing temperatures. Another design is to weld strips of metal together to create a fluid reservoir at each end of the table with inlets and outlets for circulation of warm and cold solutions on either end. The circulating baths can be positioned on the floor beneath the table or on a separate juxtaposed table. Electric thermogradient tables with heating coils and/or Peltier cooling modules have been built but high cost, challenges generating consistent low temperatures, and reliability issues have prevented widespread commercial use ${ }^{8}$.

The circulating fluid designs passively create a one-dimensional gradient via thermal conduction. If the aluminum plate is of uniform shape and thickness and properly insulated, heat flows uniformly from the warm to the cold end of a table establishing a continuous one-dimensional temperature gradient, following the second law of thermodynamics ${ }^{7}$. The gradient across the surface is a function of the table length and the differences between the end temperatures. The table and plumbing are usually housed in an insulated enclosure with lids for access. The enclosure isolates the table from its surroundings, creating a uniform gradient across the surface with little temperature variation. The insulated enclosure can be supported by legs or placed on a flat surface such as a table or bench. For applications where uniform temperature control is needed without a gradient, a table may be set up to produce isothermal conditions if both ends circulate fluid at the same temperature.

When the gradient table is functioning correctly, Petri dishes, sealed plastic bags, flat-bottomed containers, etc., are placed on the surface and thermo-equilibrate to the various temperatures (Figure 1). The experimental temperature in each container depends on airspaces that may exist between the container and the table surface and the thickness and insulating properties of each container. The gradient table effectively maintains sample temperatures close to the surface, but control is lost above the surface. The lack of vertical temperature control limits the types of experiments possible on a traditional gradient table. 
Aluminum strips or gussets were added to the traditional gradient table design to improve temperature control above the table surface. Gussets were welded at intervals perpendicular to the table surface. The gussets facilitate convective heat flow vertically above the flat table surface. Samples placed between gussets, have temperature-regulated surfaces on three sides providing more effective temperature control. Clegg and Eastin $^{2}$ placed quartz sand on a gradient table surface to create temperature control in depth. Clegg and Eastin ${ }^{2}$ also experimented with placing insulation on top of the table. Webb et al. ${ }^{9}$ placed pipes filled with soil on a table in an effort to uniformly control temperature.

The new table design reported here has nine $7.6 \mathrm{~cm}$ ( 3 inches) high gussets (aluminum strips) that are welded to the surface over the length of the table (Figure 2). LED light fixtures emitting photosynthetically active frequencies are installed on the sides of the table to support seedling growth when the table is closed. The insulated enclosure for the gusseted thermogradient table is constructed of a white PVC boards that are water, warp, and crack resistant. The purpose of this paper is to describe the new gusseted gradient table design and possible applications.

\section{Preparation of the Circulating Baths and Table}

1. Acquire two circulating baths with reservoirs that pump at least $10 \mathrm{~L} / \mathrm{min}$ to control temperature at each end of the thermogradient table. NOTE: One of the circulating baths must refrigerate the reservoir while the other needs only to heat.

2. Inspect circulating baths to make sure their filters and reservoirs are clean.

3. Identify a location for the table and baths. Position the baths beneath the table as long as the pump can circulate fluid through the table above. Place the gradient table at a convenient height to remove lids and reach all positions on the surface.

NOTE: The location for the table and baths must be well ventilated, free of extreme temperatures, relatively dust free, and have access to electrical circuits to adequately power the baths and lighting system.

4. Fill each bath to the top of the reservoir tank with a mixture of water and antifreeze $(1: 1$ ratio) to improve heat exchange and prevent freezing NOTE: The concentration of antifreeze depends on the bath specifications and temperature of the solution. High antifreeze concentrations are not required unless subfreezing temperatures are generated. Pure antifreeze may damage certain water bath pumps.

5. Connect the inlets and outlets of the baths with flexible tubing to the outlet and inlet pipes on the table, respectively, to create a continuous flow pattern at both the opposing warm and cold ends of the table.

6. Use thick-walled flexible plastic tubing with inelastic walls that will not expand under pressure or kink when bent. Use collared-screw, hose clamps at the tube unions to maintain a drip-free connection when the system is pressurized. Wrap the circulation tubing with foam pipe insulation to reduce heat exchange with the surrounds.

7. With the pipe valves open, momentarily turn on the circulating pumps to check for leaks and collapsed tubing that may reduce flow. Adjust screw clamps if leaks occur. Check lighting fixtures to ensure they are operating properly.

\section{Preparation of the Table for Experimentation}

1. Line the bottom of the thermogradient table between gussets with hydrophilic material such as greenhouse capillary matting, paper towels, or nonglossy newspaper to distribute water more evenly.

2. Fill the table uniformly with a growing media to below or even with the tops of the gussets. Pack the growing media tightly enough to remove air pockets that interfere with temperature equilibration. NOTE: Native soil can also be used.

3. With the table inlet and outlet pipe valves open, activate the circulating bath by setting one bath to a temperature $5{ }^{\circ} \mathrm{C}$ below and the opposing bath to a temperature $5{ }^{\circ} \mathrm{C}$ above the minimum and maximum desired temperatures $\left(5\right.$ to $\left.40{ }^{\circ} \mathrm{C}\right)$, respectively, to account for heat loss and gain during circulation. Monitor the reservoir baths and add a mixture of water and antifreeze (ethylene glycol) as needed when the levels fall as the circulating solution fills the pipes in the table.

4. Adjust bath temperatures until the desired growing media temperatures ( 5 to $40^{\circ} \mathrm{C}$ or other desired experimental temperatures) are achieved on the gradient table.

NOTE: The exact temperature is achieved through an iterative process of measuring growing media temperature and adjusting the baths until the desired growing media temperatures are reached across the table.

5. Place temperature dataloggers at different positions on the table to record the temperatures of the growing media or soil during an experiment. The dataloggers recommended are similar in size to a miniature round wafer battery. Wrap the dataloggers in Parafilm to prevent water damage and place at experimental positions in the growing media.

6. Wet the growing media uniformly to $70-80 \%$ of maximum water-holding capacity of the media. Wetter soils conduct heat more efficiently between gussets.

NOTE: Water tends to evaporate more rapidly from the warm end of the table, so more frequent applications may be required to replace evaporative losses. Maximum water holding capacity is the amount of water retained in the growing media after saturation and drainage of gravitational water for 2 days through a container with a perforated bottom. The moisture content was determined gravimetrically before and after oven drying at $105^{\circ} \mathrm{C}$ for $72 \mathrm{hr}$.

7. Allow the table to equilibrate for $24 \mathrm{hr}$ to ensure the desired temperatures $\left(5\right.$ to $40{ }^{\circ} \mathrm{C}$ ) are reached throughout before beginning an experiment.

8. Tilt the table by adjusting the feet at each corner until the table slopes very slightly toward the corner with the drain. This removes excess moisture, prevents wet spots on the table, and encourages uniform media moisture content. Place a container beneath the drain to catch runoff.

9. Plant seeds in growing media and water daily or as needed to keep media moist.

NOTE: As an example of how germination testing may be conducted, we planted 25 seeds of tomato (Solanum lycopersicum L. cv. Legend), melon (Cucumis melo cv. Hales Best Jumbo), lettuce (Lactuca sativa L. cv. Black Seeded Simpson), and oat (Avena sativa L. cv Swan) $2 \mathrm{~cm}$ deep.

10. Count the number of emerged seedlings daily to calculate mean time to emergence according to the equation: 
MTE $=\frac{\sum\left(n_{i} \times t_{i}\right)}{\sum\left(n_{i}\right)}$

NOTE: Where $n_{i}$ is number of emerged seeds at time $t_{i}$; $t$ is number of days from the beginning of emergence; and $\sum n_{i}$ is total number of emerged seeds.

\section{Operating the Thermogradient Table}

1. After adjusting the baths to the desired temperatures, replace the two thermogradient table covers, the transparent inner-acrylic sheet lids and a more substantial polyvinyl chloride (PVC) lid insulated with polystyrene, to enclose the table. Both covers in place provide the best insulating properties to reduce heat and water loss during testing.

NOTE: If ambient light or auxiliary lighting is mounted above the table, only the inner lid may be used to transmit light.

2. Remove the outer lid to check the table through the inner-acrylic lids. Remove the inner lid temporarily to add water or other inputs, check temperature, or record data.

NOTE: At higher temperatures, water evaporates rapidly from moist soil and condenses on the bottom of the inner lid because the surface is cooler.

3. Monitor the system closely during experiments for power outages, bath malfunctions, leaks, or excessive fluctuations in table temperatures. Monitor the bath reservoir level and periodically add fluid to replace evaporative losses.

\section{Representative Results}

Shallow containers, like Petri dishes, may be positioned on a traditional one-dimensional gradient table so the effects of multiple experimental temperatures can be assessed simultaneously (Figure 1). To increase the diversity of research applications possible on a thermogradient table $7.6 \mathrm{~cm}$ (3 inches) tall aluminum gussets were stitch welded alternately on both sides so each gusset stands perpendicular to the surface 10.9 $\mathrm{cm}$ (4.2 inches) apart in intimate contact with the surface (Figure 2). While a broad range of gusset spacings are possible, $10.9 \mathrm{~cm}$ was selected to accommodate square plastic "sandwich" boxes or similar sized containers often used to test germination of small seed species or other biological specimens (Figure 3). Unlike a conventional flat gradient table, the gusset design accommodates soils and other amorphous friable materials for controlled temperature experiments. To remove excess water, a screened and filtered drain hole was built into one corner. Shims or "feet" at each corner can be adjusted to tilt the table to facilitate gravity drainage. A small gap between the gusset ends and the outside of the table allows water to flow along one side to the corner drain.

Soil temperatures were measured at $70-80 \%$ soil moisture content after the baths had been circulating at constant temperature for 24 hr with the lids in place (Figure 4). The temperature variation measured after a $12 \mathrm{hr}$ equilibration period at four different positions across the table was $0.4{ }^{\circ} \mathrm{C}$ or less (Figure 4). Variation in the soil profile temperatures measured at three soil depths was greater at the extremes. At a target temperature of $13^{\circ} \mathrm{C}$, dataloggers placed on the aluminum surface between gussets recorded a mean of $11.0 \pm 0.0^{\circ} \mathrm{C}$. Loggers placed on the soil surface averaged $13.5 \pm 0.1^{\circ} \mathrm{C}$. The overall average soil temperature at all three levels for the target temperature of $13^{\circ} \mathrm{C}$ was $12.3 \pm 0.1$ ${ }^{\circ} \mathrm{C}$. At a target temperature of $18{ }^{\circ} \mathrm{C}$, the average temperature throughout the soil profile was $19.1 \pm 0.1{ }^{\circ} \mathrm{C}$. Variation at the target temperature of $23^{\circ} \mathrm{C}$ was greater than at $18^{\circ} \mathrm{C}$ with an average of $23.8 \pm 0.2^{\circ} \mathrm{C}$. At the other extreme temperature, $29^{\circ} \mathrm{C}$, the table aluminum surface temperature was $30.8 \pm 0.2{ }^{\circ} \mathrm{C}$ while the soil surface temperature was $25.7 \pm 0.4{ }^{\circ} \mathrm{C}$. The overall average soil temperature at $29{ }^{\circ} \mathrm{C}$ was $28.2 \pm$ $0.3^{\circ} \mathrm{C}$ (Figure 4).

Seed species can be tested for their optimum germination and seedling growth temperatures on a thermogradient table with gussets. Tomato and melon, both considered warm-season crops, germinated over a range from 14.1 to $40.2{ }^{\circ} \mathrm{C}$ (Table 1, Figure 3). LED arrays mounted in the table lids and/or sides emit the photosynthetic spectrum enabling plants to grow in soil at experimental soil temperatures when the table is enclosed (Figure 3). Optimum seedling growth for tomato occurred at $29.6{ }^{\circ} \mathrm{C}$ with an emergence percentage of $100 \%$ and a mean time to emergence of 5.3 days (Table 1, Figure 5). Emergence was slower at other temperatures. For melon, the optimum emergence percentage was $96 \%$ and mean time to emergence was 5.1 days both at $24.7^{\circ} \mathrm{C}$ (Table 1). Both lettuce and oat are considered cool-season crops. Oat seeds germinated over a range from 5.1 to $40.2^{\circ} \mathrm{C}$ the broadest of any seed tested (Table 1, Figure 5). For oat, the highest emergence percentage was $100 \%$ at $24.7^{\circ} \mathrm{C}$ and the fastest emergence was 3.4 days at $29.6^{\circ} \mathrm{C}$ (Table 1, Figure 5). For lettuce, emergence was observed over a range of 5.1 to $29.6{ }^{\circ} \mathrm{C}$. For lettuce, the highest emergence percentage was $100 \%$ at $24.7^{\circ} \mathrm{C}$ and the fastest emergence was 3.4 days at $29.6{ }^{\circ} \mathrm{C}$ (Table 1). 


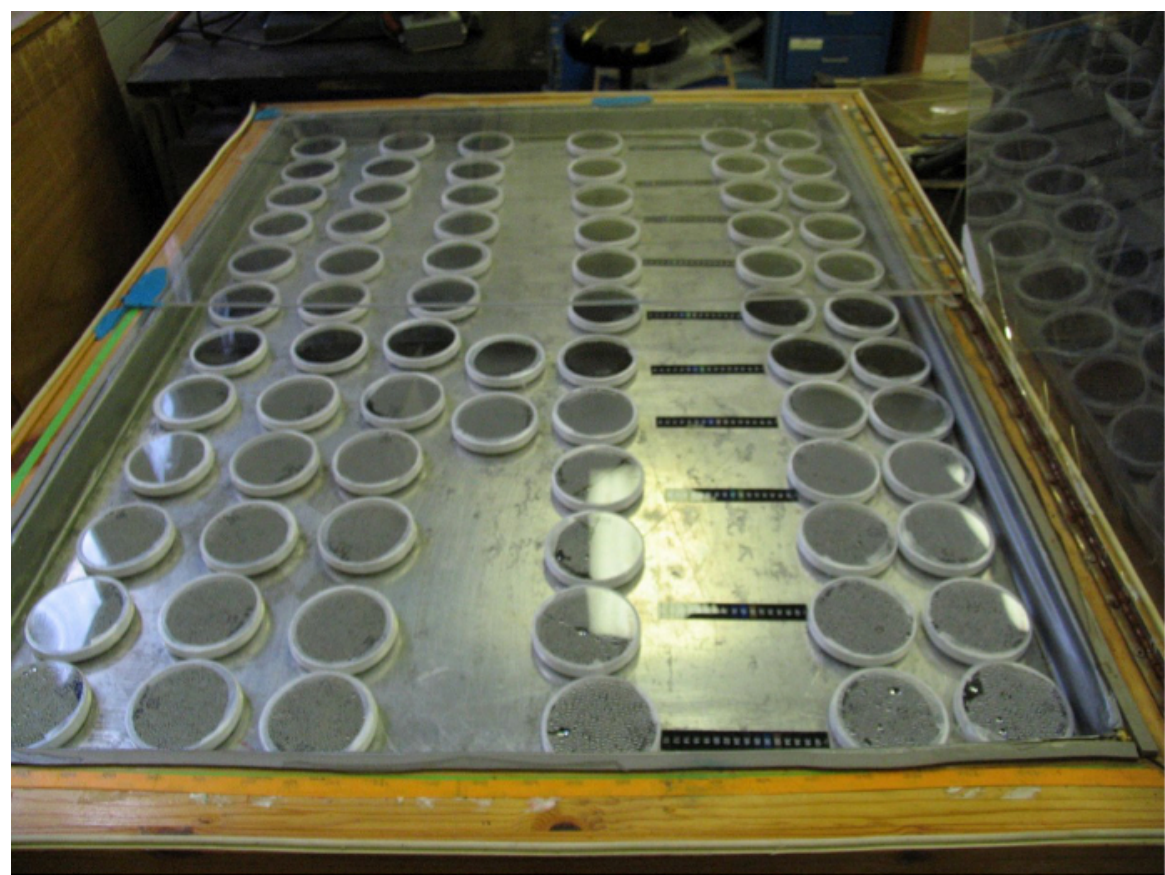

Figure 1: A traditional flat thermogradient table with the insulated lids removed but with an inner acrylic lid covering $1 / 2$ the table. The traditional flat table design tests effects of temperature on samples in shallow containers. Temperature control of the gradient is rapidly lost at distances above the surface since there is no barrier to air mixing. Experiments that required a consistent temperature in depth are not feasible using this design. Please click here to view a larger version of this figure.

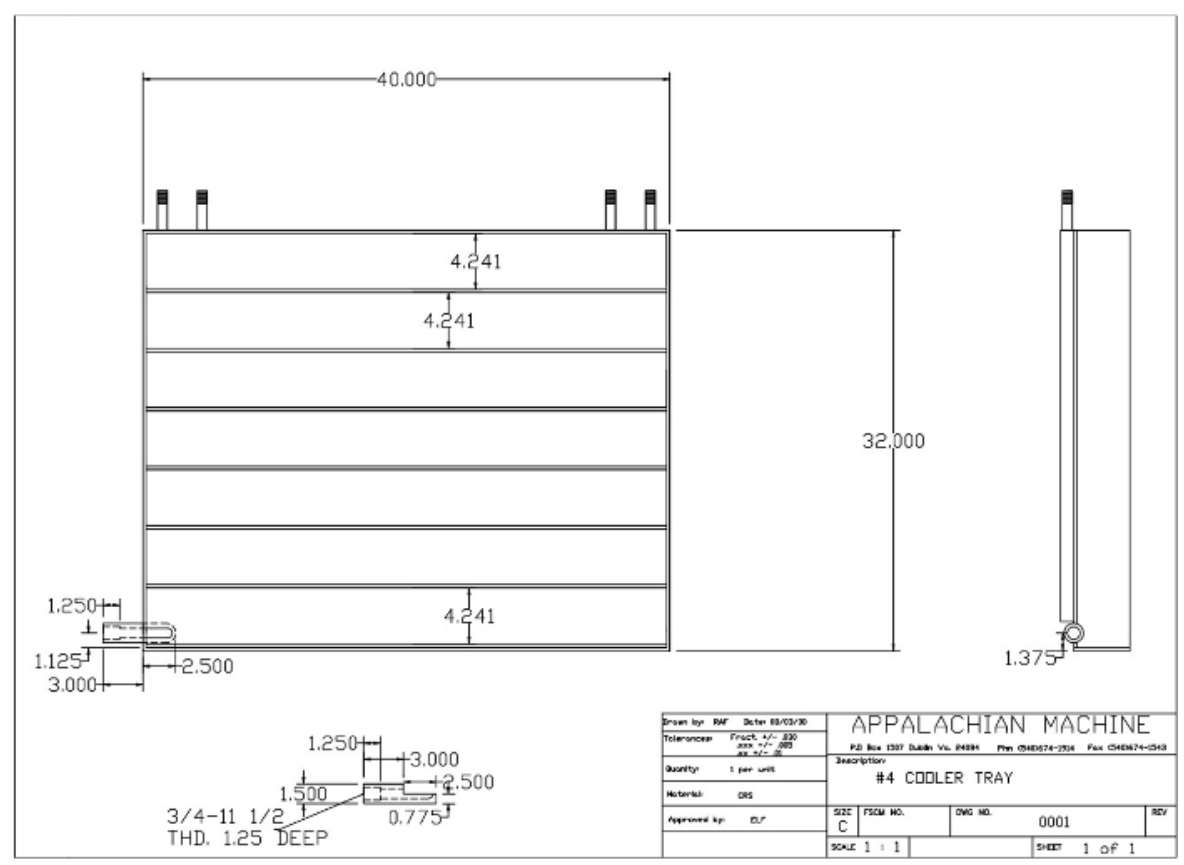

Figure 2: Schematic diagram of a thermogradient plate with gussets. Gussets are stitch welded longitudinally across the table perpendicular to the surface. A drain in one corner removes excess water. Please click here to view a larger version of this figure. 


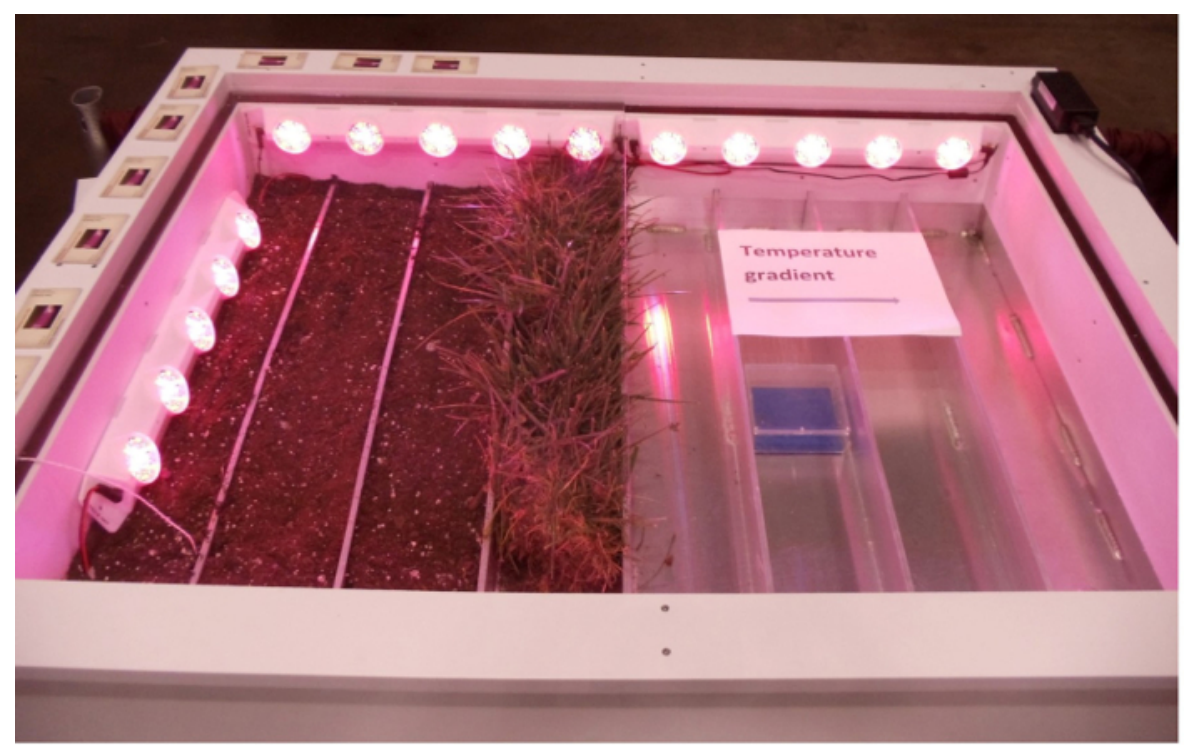

Figure 3: Illuminated thermogradient table with gussets filled with soil, sod, and containers for seed germination experiments. The gradient in this table is set up from left (warm end) to right (cold end). While the gusset design was developed for use with soil, containers can be placed between gussets for experiments with small specimens. The LED plant grow lights may be mounted in the lids or periphery and emit photosynthetically active frequencies and allow plants to be grown inside the enclosure. Please click here to view a larger version of this figure.

"Left Wall $\quad$ "Left Center $\quad$ Right Center $\quad$ Right Wall

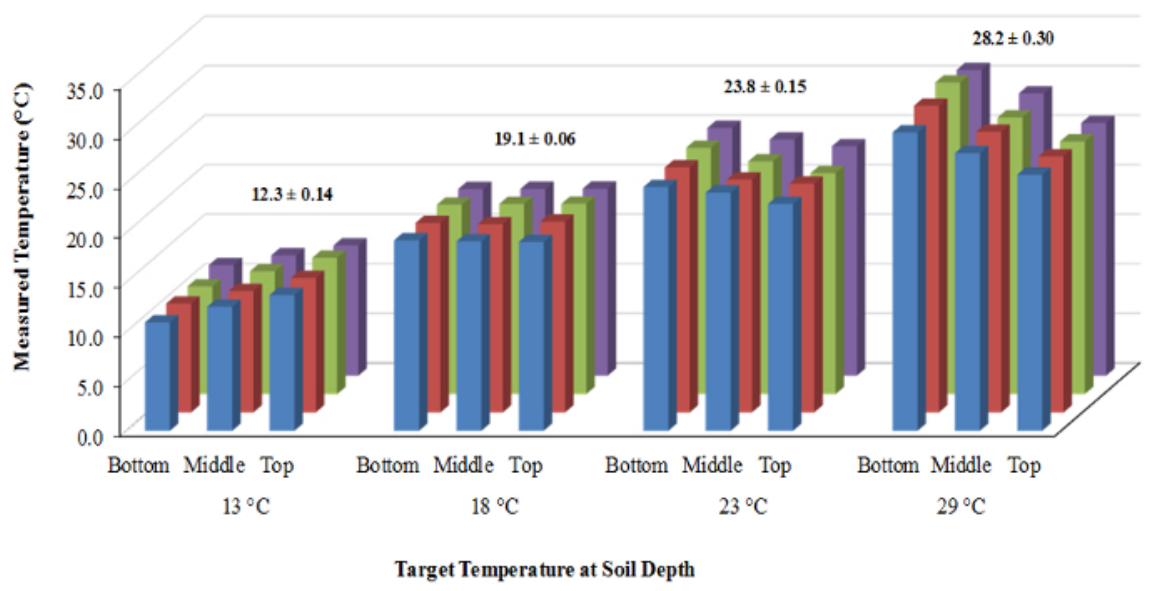

Figure 4. Temperature readings from different soil positions on a gusseted thermogradient table. Temperature loggers were placed in soil across the table at the left wall, left center $(20 \mathrm{~cm}$ from the left wall), right center $(40 \mathrm{~cm}$ from the left wall), and at the right wall midway between gussets. Bottom positioning of temperature logger was near the aluminum table surface $8 \mathrm{~cm}$ below the top of the soil while center placement was approximately $4 \mathrm{~cm}$ below the soil. Temperature loggers placed on top of soil were uncovered. Values above bars indicate the overall mean temperatures \pm standard error of the mean $(n=72)$. Please click here to view a larger version of this figure. 


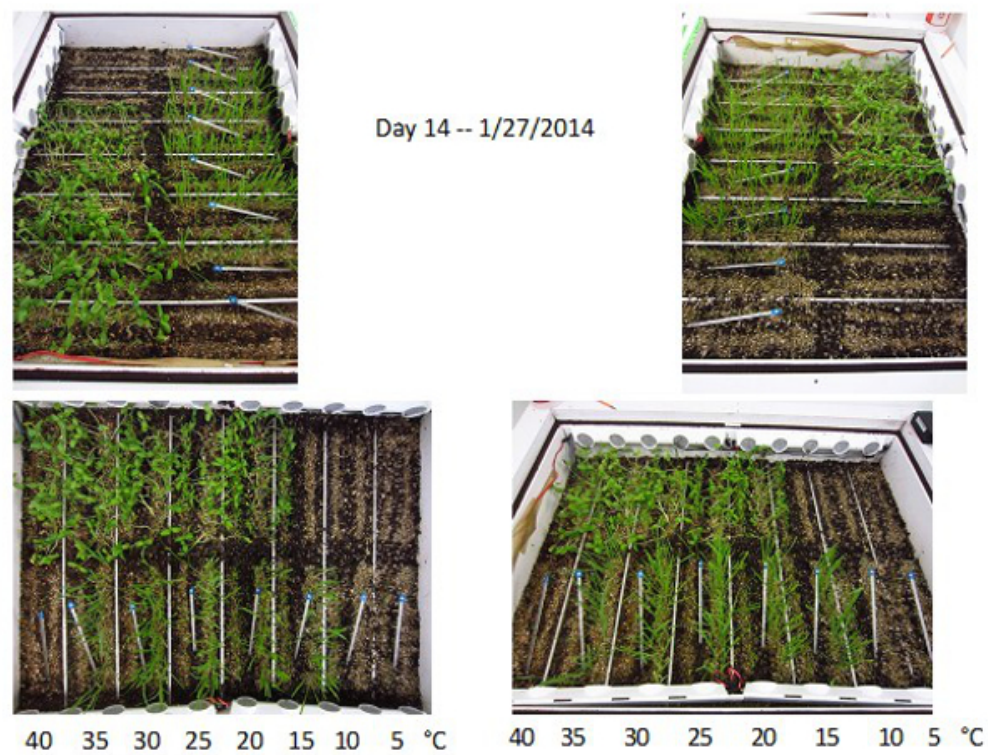

Figure 5: Seedlings of oat and tomato grown for 14 days on thermogradient tables over a temperature range of 5 to $40{ }^{\circ} \mathrm{C}$. The picture illustrates how germination and seedling growth of multiple species can be assessed in soil simultaneously over a range of temperatures in a single experiment to simulate field conditions. Top (left and right) pictures show the thermogradient table when viewed vertically. Bottom (left and right) pictures show the table in horizontal orientation. Alcohol thermometers were placed in the soil to rapidly monitor temperatures throughout the experiment.

\begin{tabular}{|c|c|c|c|c|c|c|c|c|c|}
\hline \multirow{2}{*}{$\begin{array}{l}\text { Target } \\
\text { Temperature }\end{array}$} & \multirow{2}{*}{$\begin{array}{l}\text { Measured } \\
\text { Temperature }\end{array}$} & \multicolumn{2}{|c|}{ Tomato } & \multicolumn{2}{|c|}{ Melon } & \multicolumn{2}{|c|}{ Lettuce } & \multicolumn{2}{|l|}{ Oat } \\
\hline & & EM † & MTE†† & EM & MTE & EM & MTE & EM & MTE \\
\hline${ }^{\circ} \mathrm{C}$ & ${ }^{\circ} \mathrm{C}$ & $\%$ & days & $\%$ & days & $\%$ & days & $\%$ & days \\
\hline 10 & 8.7 & 0 & 0.0 & 0 & 0.0 & 92 & 7.5 & 58 & 12.5 \\
\hline 15 & 14.1 & 100 & 10.8 & 16 & 13.8 & 68 & 5.9 & 96 & 7.2 \\
\hline 25 & 24.7 & 100 & 6.0 & 96 & 5.1 & 22 & 8.1 & 100 & 3.7 \\
\hline 30 & 29.6 & 100 & 5.3 & 92 & 5.5 & 4 & 12.5 & 98 & 3.4 \\
\hline 35 & 36.1 & 94 & 7.0 & 92 & 4.4 & 0 & 0.0 & 94 & 4.5 \\
\hline 40 & 40.2 & 72 & 7.8 & 88 & 5.1 & 0 & 0.0 & 10 & 8.2 \\
\hline
\end{tabular}

† Successful emergence (EM) was scored when seedlings had at least one open cotyledon.

$\dagger \dagger$ Mean time to emergence (MTE) was calculated by summing the product of the number seeds that emerged each day by the day number and dividing by the total number of seeds that emerged for each treatment.

Table 1: Germination of Tomato, Melon, Lettuce and Oat Seeds in Soil at Eight Temperatures on a Thermogradient Table. Bold numbers show optimum values for each species and illustrate the temperature dependence of different crop species. The experiment was conducted for 14 days in potting mix and the media was watered daily or as needed to keep soil visibly moist. Data are based on 25 seeds for each species.

\section{Discussion}

Thermogradient tables have been used for many years for conducting primarily seed germination experiments in shallow containers over a range of temperatures simultaneously. However, the experimental temperatures are limited to the table surface so the depth of temperature control is limited. Seed testing protocols conducted on traditional gradient tables end with radicle emergence on paper substrate in Petri dishes or other flat containers and do not realistically test seedling emergence and growth as would naturally occur in soil. Today seed companies often wish to assess seed vigor (the ability to germinate under less than optimum conditions) using simulated field conditions that growers will likely encounter after planting. Soil testing also exposes seeds to fungal and bacterial disease pressures not common in standardized laboratory germination tests on soilless media. When soil is placed on a flat non-gusseted table, large variations of $5^{\circ} \mathrm{C}$ or more were not uncommon between positions in the soil profile and table surfaces (unpublished results).

A one-dimensional gradient table with gussets was developed to improve vertical temperature control so that soil could be used in germination tests and other experiments where accurate control of soil temperature is critical. The gussets confine soil or synthetic growing media and control temperature in depth. The gussets are aluminum, the same material as the tabletop, and when welded perpendicular to the surface they provide 
temperature control of the space between by conductive heat transfer. The gussets can be oriented lengthwise down the table or widthwise across the table. Both designs perform similarly but the widthwise gusset orientation is convenient because the space between gussets may serve as a single experimental temperature when the gradient is properly adjusted. Horizontal orientation allows experimental units (seeds in this example) to be spaced across the table in a line next to one another. Gusset spacing can only be varied during manufacturing because gussets are welded in place so alternative positioning cannot be tested once table construction is completed. A gusset spacing of $10.9 \mathrm{~cm}$ was selected to accommodate shallow containers often used for seed testing in addition to soil. Closer gusset spacing may provide better temperature control but would limit the types of containers that can be used on the table.

The temperature and moisture of the growing media in the thermogradient table must be continually monitored to achieve the desired experimental conditions. Before planting, the circulating baths should be set slightly below the desired minimum and slightly above maximum temperatures than adjusted until the samples have reached the desired experimental temperatures. Approximately $24 \mathrm{hr}$ should be allowed for the samples to thermal equilibrate with the gradient table. The moisture content of the growing media should be sufficient $(70-80 \%$ of field capacity) for seed germination or other biological processes to proceed. The table insulation and dual lids reduce temperature fluctuation and water evaporation when in place.

The results in Table 1 compare seedling growth of 4 species at different temperatures. The growth of melon and tomato seeds began at 15 ${ }^{\circ} \mathrm{C}$ and germinated well at $40^{\circ} \mathrm{C}$ explaining why they are characterized as warm-season crops ${ }^{10}$. In contrast, lettuce germinated best at low temperatures. Oat seed germinated over a broader range of temperatures than the other species (Table 1). While similar results could be obtained using a series of growth chambers in a series of coordinated experiments, the gusset design allows both germination and seedling growth to be compared over a range of soil temperatures simultaneously. Different field soils or growing media may be substituted to simulate a range of field conditions. Microbial or chemical treatments, fertilizer regimes, drought stress, and variations in light environment can be imposed across temperatures on the gradient table.

The small dataloggers recorded temperature at various positions on the table. Temperature data showed, relatively uniform temperatures in the middle of the table with greater variation, particularly at the warm end. Positioning loggers in contact with the table surface and exposed to the air on the soil surface likely accentuated the extremes. Temperatures recorded at the center position were probably more indicative of bulk soil conditions. For example, a seed planted in the soil on the gradient table between gussets to simulate field planting would only be exposed to bulk soil temperature and not the air or the table surface temperature. The moisture content and texture of soil plays a role in determining table temperatures. If the soil is dry, air spaces resist temperature change and do not effectively conduct heat from the gussets. Moist soil has few air spaces and more liquid water to effectively conduct heat through the soil profile. In this experiment, soil was maintained at 70 to $80 \%$ of its maximum water holding capacity but higher water content may have reduced soil temperature variation. Sand has as fewer large pore spaces than soils with high organic matter and thus would be expected to provide more uniform temperatures.

There was greater variation in soil temperature at the warm end of the table compared to the cold end. One possible explanation lies in the distribution of moisture across the table. Moisture tends to be retained in the cold end, while the warm end tends to dry out because of greater evaporative losses. Since water helps conduct heat, it is important that the moisture content of the table be as uniform as possible. Webb et al. ${ }^{9}$ used blotter paper to conduct water across a thermogradient table via capillary action, while newspaper worked well as a less expensive alternative in the gusseted thermogradient table. Even though gussets were lined with hydrophilic paper to add moisture distribution, keeping both the cool and warm ends uniformly wet is challenging.

Rapid evaporation at high temperatures occurs on all gradient table designs. Condensation is often a problem when container experiments are conducted on a gradient table at temperatures much above ambient because the bottom of the container is warmer than the top causing water to collect on the inner side of the cooler lid. In soil experiments on the gusseted table, water evaporated from the upper soil layers into the air above in the gusseted table. If the soil is very wet, evaporative losses at the warm end of the table may condense on the cooler inner-acrylic lid. Resting tight-fitting pieces of acrylic or polystyrene insulation directly on top of the gussets minimizes vapor exchange with the airspace above the table keeping the soil more uniformly moist and temperature constant (data not shown). When the table was covered with polystyrene insulation, temperature variation was only from 1 to $2{ }^{\circ} \mathrm{C}$ through the soil profile at the temperature extremes (data not shown). However, polystyrene insulation prevents seedlings from emerging and must be removed after the initial hr of incubation for growth analyses. Another solution to prevent rapid drying of warm soils is to preferentially add more water to the warm end to compensate for evaporative losses. Hand watering is problematic because the lids must be removed and application volumes are less precise. Micro-irrigation emitters can be designed onto a gradient table and can be adjusted to preferentially apply more water to the warm end.

Thermogradient tables have the functionality and potential to serve as alternative growth chambers. When both baths are set the same, the table equilibrates to single experimental temperature for applications where a gradient is not required. Day and night light and temperature fluctuations can also be simulated using programmable circulating baths and LED grow lights. Populating the insides of the lids with LED grow lights can increase lighting intensity. The LED grow lights input minimal heat into the system and did not interfere with the gradient because similar soil temperatures were recorded with lights on and off (data not shown). The addition of lights enables plant growth and greater environmental control.

Thermogradient tables have been used primarily by the seed industry for germination studies in the past, but many other applications are possible. Insect behavior has been studied on a gradient table to determine temperature optima of certain behaviors ${ }^{11}$. Ice can be frozen on a gradient table surface for testing phenomena at subfreezing temperatures (data not shown). Gas exchange between the soil and atmosphere, including carbon dioxide evolution, is possible on a gusseted gradient table at varying water contents, soil inputs, and temperatures. Studying effects of bacterial and fungal growth in different types of media over a range of temperatures is also possible with this experimental system.

\section{Disclosures}

The authors have nothing to disclose. 


\section{Acknowledgements}

We thank Kent J. Bradford and his students at the UC Davis Seed Biotechnology Center for recording seedling emergence data.

\section{References}

1. Chatterton, N.J., \& Kadish, A.R. A temperature gradient germinator. Agron. J. 61(4), 643-644 (1969).

2. Clegg, M.D., \& Eastin, J.D. A Thermogradient generating sand table. Agron. J. 70(5), 881-883 (1978).

3. Evans, R.A., Young, J.A., Henkel, R., \& Klomp, G. A low temperature-gradient bar for seed germination studies. Weed Science. 18, 575-576 (1970).

4. Grime, J.P., \& Thompson, K. An apparatus for measurement of the effect of amplitude of temperature fluctuation upon the germination of seeds. Annals of Botany. 40(4), 795-799 (1976).

5. Halldal, P., \& French, C.S. Algal growth in crossed gradients of light intensity and temperature. Plant Physiol. 33(4), 249-252 (1958).

6. Thompson, K., \& Whatley, J.C. A thermogradient apparatus for the study of the germination requirements of buried seeds in situ. New Phytologist. 96, 459-471 (1984).

7. Bergman, T.L., Incropera, F.P., \& Lavine, A.S. Fundamentals of Heat and Mass Transfer. John Wiley \& Sons, (2011).

8. McLaughlin, N.B., Bowes, G.R., Thomas, A.G., Dyck, F.B., Lindsay, T.M., \& Wise, R.F. A new design for a seed germinator with 100 independently temperature controlled cells. Weed Research. 25, 161-173 (1985).

9. Webb, D.M., Smith, C.W., \& Schulz-Schaeffer, J. Amaranth seedling emergence as affected by seeding depth and temperature on a thermogradient plate1. Agron. J. 79(1), 23-26 (1987).

10. Welbaum, G.E. Vegetable Production and Practices. CAB International, (2015).

11. Swoboda, L.E. Environmental influences on subterranean termite foraging behavior and bait acceptance. Ph.D. diss., Virginia Polytechnic Institute and State University, (2004). 